\title{
Keeping it Social: Engaging Students Online and in Class
}

\author{
Jennifer J. Peck ${ }^{1}$ \\ ${ }^{1}$ Department of Linguistics, Faculty of Human Sciences, Macquarie University, Sydney, Australia \\ Correspondence: Jennifer J. Peck, Department of Linguistics, Faculty of Human Sciences, Macquarie University, \\ Sydney, NSW, 2109, Australia. E-mail: Jennifer.Peck@mq.edu.au
}

\author{
Received: September 3, 2012 Accepted: September 24, 2012 Online Published: October 31, 2012 \\ doi:10.5539/ass.v8n14p81 \\ URL: http://dx.doi.org/10.5539/ass.v8n14p81
}

\begin{abstract}
New technologies expand the horizons of education, offering opportunities to explore practices based on collaboration and community rather than the individual teacher or learner. A social networking site was implemented in a university unit with the aim of progressing online participatory culture and increasing student engagement both online and in face-to-face classes. The challenge of engaging students and converting lurkers and stalkers into talkers is discussed.

Analysis of linguistic features of blog and forum posts was undertaken and the findings were used to modify online instructor behaviour and presence, and to encourage student participation. The research found that posts with high response rates had short topic titles, used directives and lexical items suggesting immediacy: "Newest hottest topic", while modalization and requests for help produced low or zero responses. Controversial topics received most responses. Gender was found to be a relevant factor, with blogs posted by males gaining higher response rates than those posted by females. The online site produced discursive shifts in "real life" interactions, and provided a speaking-space for quiet students.
\end{abstract}

Students' initial cynicism towards the site changed, and online social networking cultivated affinity groups and increased student participation in both online and face-to-face contexts.

Keywords: collaborative learning, increasing participation online, instructor presence online, gender and language, blogging skills

\section{Introduction}

\subsection{Overview}

New technologies provide stimulating opportunities for innovative teaching and learning. Novel applications have the potential to engage students and develop collaborative and egalitarian learning and teaching spaces. It is an era of rapid global innovation that involves a shift in concepts of literacy to include social literacy: skills developed through online collaboration and networking (Gee, 2004; Greenhow \& Robelia, 2009; Jenkins, Clinton, Purushotina, Robinson, \& Weigel, 2009).

The contemporary student brings to their learning new expectations regarding involvement and contribution: students are increasingly involved in decisions about what will be prioritized in the media; what will be debated in their social lives and in wider networks, and whose voices will be heard (cf Jenkins et al., 2009). It is arguably implicit in this involvement that students will expect to collaborate in the process of production of their education. While this expands horizons beyond traditional practices for educators, they are simultaneously faced with the need to make effective use of new technologies. The project discussed here shows that the implementation of an essentially "social" online site presents challenges in relation to both the engagement of students and the behaviours and type of presence adopted by the instructor.

Online social networking through a NING site was introduced as part of a Linguistics unit at Macquarie University, Sydney, Australia. The proposal was that by providing opportunities to interact freely online, students would participate more in tutorials and lectures, student confidence would be increased and social literacy advanced. The paper examines the semester-long project, discussing students' initial resistance and describing how linguistic analysis of blog and forum posts was used by the instructor to encourage online participation. The project resulted in enthusiastic online blogging and the development of engaged student communities both online and in face-to-face classrooms. 


\subsection{Background}

Jenkins et al. (2009) examine online culture in the context of new directions in education and types of literacy, and argue that key to the concept of participatory culture is that it is an online culture in which members feel socially connected, and that this online culture provides strong support for creating and sharing. In this culture everyone is free to contribute when they are ready, and what they contribute will be valued (Jenkins et al., 2009). The "affinity spaces" (Gee, 2004) associated with online cultures provide informal experimental learning environments compared with typically static formal education. The informal environments of social networking such as You Tube, Facebook and Twitter often evolve to respond to short-term needs and temporary interests, which contrasts with the processes of much traditional education (cf Jenkins et al., 2009). It may be suggested that much contemporary use of new technology in education essentially replicates, or at least relies on, traditional formal educational strategies. Many online discussion boards tend to focus on course content with blogging as a requirement or marks being allocated for contributions. The technology is rapidly being adapted, however, to foreground social and community processes. Wallace and Howard (2010) used online facilities to encourage collaborative cohorts of students who were geographically distant, and found that students both work online on assignments together, and provide each other with emotional support. A number of online courses or online classrooms prioritize community (see Swan \& Shea, 2005), with positive results, and there are beneficial outcomes when the course strives towards the spirit of community (Thompson \& MacDonald, 2005).

The online culture of connectedness, support for the group, and dynamic student-driven dialogues suggests transformative possibilities for face-to-face classroom learning situations. A fundamental principle of online participatory culture connects with my key teaching aims: to encourage all students to participate, and to make available a safe space that encompasses community and support. An early recognition of the opportunities provided by computer mediated education was made by Garrison et al. (1999), who linked online social presence to risk-free expression, collaboration and open communication: this project connects with and extends these notions. The project discussed in this paper aimed to provide a familiar online social space with an engaged online student community and to explore whether this translated into increased participation and connectedness in face-to-face classes.

My previous experience was that debates and discussions in lectures and tutorials were dominated by a minority of confident and vocal local Australian students, while most students, perhaps because they were quiet or concerned that what they said might be inappropriate, remained silent. International students, (especially students from China, Japan, Korea and Vietnam), were usually reluctant to contribute to class discussions. Some international students have also told me that they have found traditional online discussion forums to be a source of stress and intimidation because they felt pressure to write complex, error-free English. It was hoped that students' familiarity with social networking on sites such as Facebook would enable their development of confident voices: "talking" online could extend to speaking in class.

The project described here foregrounds the social element of online activity, encouraging social interaction rather than focusing on formalized discussion topics. The Results and Discussion section of this paper describes the relationship between topics and social engagement, and shows that while activities related to unit content were useful, unit-related topics did not serve to engage the whole student community, or to generate egalitarian social connectedness. It is argued that online affinity spaces prioritize collective intelligence and the communal voice (Gee, 2004; Jenkins et al., 2009). Posting on unit-related topics might implicitly contradict notions of equality of knowledge by foregrounding concepts of formal education. This might reinforce traditional teacher/learner roles and produce discourses that highlight individual rather than collective intelligence. In addition, these topics might encode instructor behaviour that is inappropriate for a social site (cf Swan \& Shea, 2005), and ultimately result in too much teacher presence (cf Mazzolini \& Maddison, 2003). This online site involved the modification of instructor presence and revealed that while the instructor was welcomed in some online spaces, participation in other spaces was effectively constructed as inappropriate by students. This issue is part of an ongoing debate between educational technology bloggers (see e.g. chronicle, n.d.; Jones, 2010).

Discursive constructions of power in online posts. and issues related to gender and orientation towards self and other were found to be relevant to gaining responses and creating a successful online site. This project advances the discussion of stylistic online differences associated with gender and power (cf Herring, Johnson \& DiBenedetto, 1992, 1995; Peck, 2006b).

\section{Method}

\subsection{Outline of the Project}

Key motivators for introducing online social networking were to increase student participation and to align the 
online facilities of the unit with the unit's subject matter. Given that the topic of the unit is online communication, it seemed appropriate, even necessary ( $\mathrm{cf}$ Webb, 2009) to include a site that was more contemporary than Blackboard, which was commonly used at Macquarie University in 2010. A Facebook link was considered, but, with similar rationale to that of Wallace and Howard (2010), Facebook was discounted on the grounds that students might consider it a privacy risk. For this unit, a NING site was opened in week 2 of semester 12010. The site was described to students in a lecture and in tutorials as a forum for discussing unit material, increasing social interaction online and in the wider university context, and as having the possibility for increasing face-to-face class participation. Students were told that membership was voluntary, not part of the assessment process, and that no adverse results would result from non-membership.

\subsection{Participants}

The participants were 50 students enrolled in a second year undergraduate unit at Macquarie University, Sydney, in 2010. The 23 male and 27 female students were aged between $18-40$ years, with 46 between the ages of 18 and 23. Of the 20 international students, 16 were from China, Korea and Japan. The local students were representative of the varied ethnic population of urban Australia: students self-identified as being of British, Chinese, Greek, Indian, Lebanese and Polish ethnicity. The corpus included three students who self-identified as gay and lesbian. Two students had not previously used online social networking.

\subsection{Methodology and Data Collection}

When the social networking site was introduced I thought, naively, that students would engage with it as they would with Facebook, but the context of institutionalized study, the presence of the convenor, and the potential for judgemental attitudes of both staff and peers made this a site of difference and resulting inhibition. The negotiation of student engagement emerged as a complex and challenging process, and the analysis of the linguistics of blog posts and the impact of instructor presence developed as a response to this problem.

When the lack of active participation was identified, blogs and forum posts were assessed in terms of the number of comments received and how response rates correlated with the topic of the original post; the linguistic framing and length of the topic line, and poster information such as gender, age, and ethnicity. Other aspects of poster identity that were treated as having possible relevance were sexual orientation, group membership and academic success. A discourse analysis approach was applied to the data and revealed practices related to identity and the non-institutionalized social power associated with successful blogging.

NING has insite links to My Page; Photos; Videos; Forum; Groups; Blogs, and Chat. The data analysis of this project focused on forum and blog postings, with the original post in a sequence being taken as the main data source. Observations of posts to the instructor on the instructor's page were also made. By the end of the semester there were 61 blog and 52 forum posts, with responses to posts being between zero and 25 .

All students enrolled in the unit chose to register on the NING site. Ethics approval was granted by Macquarie University to request students' consent to use their posts for research purposes. In order to reduce the observer's paradox (Labov, 1973) and avoid implied pressure on students to consent to the use of their posts, ethics consent forms were emailed to students after their grades had been published. All students consented.

\section{Results and Discussion}

\subsection{Student Engagement: Initial Findings}

Most students were familiar with social networking, (only two had not previously used it), and their initial response to using online networking as part of the unit was unenthusiastic, with some saying that they were very cynical about NING. The idea that online socializing would result in offline friendship was openly ridiculed: "I already have friends", said one student; "I don't want to have coffee with people from this class", said another. Webb (2009) reports that students' responses to the introduction of new technologies in his study ranged "from enthusiastic embrace through indifference to active resistance" (paragraph 2). The current project experienced much initial indifference and resistance, but little enthusiastic embrace. A reflection of students' skepticism was the slow rate of registration over the first three weeks. The early pattern was that students who were vocal in tutorials engaged in online debates, though an encouraging early event was that three students who were silent in class talked extensively online. It appeared that, while I was not engaging the silent majority, I was succeeding in enabling some reserved and thoughtful students to contribute (cf Reber, 1996). At this point the situation reflected the typically reported 90/9/1\% participation rate (Forum Doc, n.d.; Nielsen, 2006) and my challenge became to convert lurkers and stalkers into active participants.

The following discussion examines the linguistic features associated with the relative success or failure of posts, and argues that students who were skilled in blogging rhetoric contributed to wider student engagement. The key 
factor of instructor involvement as constraining uninhibited online student participation is discussed.

\subsection{Power and Discursive Practices}

The focus of this section is the challenge of both attracting students to the NING site and encouraging them to be active participants, which involved careful review of instructor posts and a modification of online teacher presence. Discursive shifts associated with teacher role in face-to-face classes is also considered.

Topic nomination was revealed as having complex meanings associated with power and context. The selection of a unit-related topic by the instructor appears to have both foregrounded the institutionalized power of the instructor, and indicated a dislocation between the stated social meanings of the site and the meanings of traditional formal study: students' non-responses indicated their effective rejection of the lecturer's engagement in some online social contexts.

My posting of cyberlanguage topics did not gain comments unless there was assessment-related motivation. Thus, while my post: "WHO'S TALKING OUT THERE? ... do this! it could help you in the test:P" gained 16 comments, my post: "EMOTICONS AND IDENTITY - GET TALKING!! :)))" received no responses. Unit-related topics posted by the instructor may have reinforced traditional teacher-student power relations, effectively undermining the social equity encoded in online participatory culture (cf Jenkins et al., 2009). My activity implicitly restated conventional education strategies: the teacher selects a topic and the students discuss it. Significant to this point is that when students posted unit-related topics, they did receive comments, with response rates apparently being triggered by the rhetorical strategies they had employed. Some of these posts will be examined later in this paper. The response pattern suggested that my presence, combined with the orientation of my posts towards scholarly content, was the prohibiting factor.

Students did visit the NING site to view information such as lecture notes and timetable information, though most did not initially post on the site. When I said in a tutorial that I had not seen them on NING, students said: "We're all there"; "We're following you"; "We want to know what you think", and laughingly agreed with my evaluation of them as lurkers and stalkers. "It's what we do on Facebook", said one student, "we stalk". I tried strategies to engage students online, and changing my profile photo produced in-class comments. Examples of this are that my online profile photo taken at a concert generated in-class discussions of bands and music; a photo in which I was riding a horse in the ocean produced discussion of horse riding, surfing and Australian lifestyle. This supported my aim that online sociability would extend into face-to-face classes and reduce traditional teacher/learner power distance. The NING site produced equitable discourses, but I was not equally welcome in all contexts of the online democratized space. I found that my engagement in student-initiated posts tended to result in the termination of a blog. Recognizing that my presence resulted in discursive shifts, I withdrew from students' communal online activities, effectively adopting the "ghost in the wings" role described by Mazzolini and Maddison (2003).

While it appeared that my presence in contexts that had been designated students' social spaces was constructed as inappropriate, in their posts to My Page students appeared to welcome me, adopting Facebook-type discursive practices, as the following online comments which feature casual address forms, short forms, emoticons and slang show:

How's it going Jen Jen!!!

\section{THANKS JEN JEN :D}

hope to hear from u soon. ps. i miss the sassy boot :P

oh nah leave it its all good

Oh really? That's a bugger, it was there at, like, $1 \mathrm{am} \backslash=\mathrm{o}($

Crap! It didn't work $=\mathrm{o}($

Acceptance in this space was confirmed by the fact that nine students asked me to be their Facebook friend, and 15 invited me to be their friend on NING. One student posted on My Page on NING:

jennifer! accept my friend request already! ==

using familiar Facebook style. The discursive modes of the My Page context transferred into tutorials, as exemplified by students greeting my arrival at tutorials with "Hey Jen Jen", or "Hey Jenny from the block". This shift in my name (from Jennifer) was unusual and limited to this student corpus. This project revealed the mutual creation of an experimental affinity space (Gee, 2004; Jenkins et al., 2009) and the informal discursive "play" which Gee (2004) and Jenkins et al. (2009) describe as part of the online affinity space extended into 
face-to-face classes. This process involved the dislocation of typical teacher/student, dominant/subordinate discourses (Merchant, 2007; Parsell \& Duke-Yonge, 2007). Males and females, older and younger students and students from all ethnic backgrounds joined to form a collective community both online and in face-to-face classes, and international students seemed to welcome the opportunity to join in the play.

Students' presentations showed how the community functioned both online and face-to-face, and this forms part of the later discussion of this paper. Further comment will also be made on the way linguistic analysis elucidates some of the complexities involved in instructor presence and behaviour in online sites (cf chronicle, n.d.; Flexknowledgy, n.d.; Hanna \& de Nooy, 2003; Jones, 2010; Mazzolini \& Maddison, 2003; Swan \& Shea, 2005).

\subsection{Online Rhetoric and Response Rates}

Of the 48 who were familiar with social networking sites, only four students consistently displayed high-level skills in using the rhetorical devices of blogging to gain responses to their initial posts from a wide student audience. Blogging rhetoric arguably involves new linguistic skills and knowledge, with smart bloggers attracting responses with language that is controversial and informal, and which uses social networking stylistics.

The discussion which follows describes successful and unsuccessful linguistic strategies and the ways in which some strategies correlate with gender of poster. A significant finding is that the most popular blogs were both male-generated and male-dominated. Plester and Wood (2009) propose that texting may provide a means to engage boys in literacy activities at a time when their literacy attainment is slipping. This project suggests that not only do young males engage with online blogging, but some display excellent social literacy in this genre.

\subsubsection{Topic Title and Informality}

Topic title was the first and most striking element of a new blog or forum post. One student posted an online question asking what makes a successful blog and all comments cited interest in the topic as the main reason for responding. Pre-existing interest in the topic was not confirmed by analysis of the data as producing responses, though other rhetorical elements related to the topic did.

Length of topic title emerged as relevant to response rate, with short titles gaining more responses than longer titles on a similar topic. Two blogs on the topic of lolcats, (photographs of cats accompanied by captions that have specific grammatical rules), provide data to support this point. The post with the title "lolcats (pics here)" received eight responses, all from different posters, while "lolcats: Permeating Popular Consciousness Since 2006" received two comments, both from the same student.

It appeared that the relative complexity and accessibility of language used was relevant to the number of comments received. The inclusion of elements with wide audience appeal was also significant. The author of "lolcats (pics here)" followed the topic line with:

I was surprised that there were so few people who knew about lolcats! Here are some examples to do with random things, Japanese Rock and Korean Pop.

The informal language of the post, the exclamation mark, and the offering of examples stated as "random", a word that is appropriate for both the generation of the audience and the social network context, appeared to make this an accessible post. Crucially, despite the statement that the examples were "random" the poster included reference to Japanese rock and Korean pop, and this post did gain responses from one Japanese and two Korean students who did not usually post. The post of one Korean student:

some of those pics give me a good laugh.

Those korean guys look familiar.

$\mathrm{r} u$ a fan?

pointed to the successful strategic moves of the original blogger. The casual language, short forms and connection with the Korean reference suggested the discursive alignment of the respondent with the blogger.

By contrast, both the title and the blog of the second example demonstrated more linguistic complexity. Both blogs started with "lolcats", but while the first post used the direct and abbreviated "pics here", the second poster used multisyllabic words, full forms and catpitalization: "Permeating Popular Consciousness". The second author continued:

The above is a link to a music blogger's review of the new album by notorious Norwegian musician/murderer/arsonist/philosopher Varg Vikernes. Because the controversy surrounding the guy is getting so tiresome, this blogger decided to avoid getting embroiled in yet another idealogical crossfire by writing the article in lolcat-speak. It's a pretty hilarious read actually. 
Does anyone else have any examples of lolcats, or internet memes in general, making their way into wider reference like that?

The blog was implicitly oriented towards readers interested in Vikernes or in debating music, philosophy or ideology. The reference to "internet memes" implied technical knowledge and that respondents would post equivalent contributions: "examples ... making their way into wider reference like that" (italics added). Only one member responded: the silence of the other 48 might mark this contribution as inappropriate for this social networking context. In blogs on social network sites where the aim is to get comments, silence is a powerful discursive tool (Herring et al., 1992, 1995; see also Tannen \& Saville-Troike, 1985). So, while collective intelligence is respected in blogging, in the construction of the communal voice some contributors are marked as peripheral by the silence of the majority.

While the previous discussion is based on limited examples, it provides useful rhetorical comparisons. The linguistic findings are supported by other data on the NING site which show that posts using informal language and including spelling errors, short forms and emoticons were more likely to generate high response rates from a wide and diverse population. NING appeared to be accepted as a site of relatively risk-free expression (cf Garrison et al., 1999): pressure to write complex, error-free English was removed, and the topics and Facebook-like discourse provided an interface between students' academic and social selves. The linguistic elements discussed here also feature in the following examples.

\subsubsection{Linguistic Features and Gender}

Directives such as "Speak"; "Have your say"; "Don't hold back"; "let loose tell us all what you really think" were found to be successful in gaining responses, while modalization such as "Perhaps someone could help" or "Can I please ask" produced few or no responses. Asking for help or advice did not typically gain a response. A post that said "I am genuinely looking for advice on this" received no responses. This seems counter to the social support element that networking usually provides, but in tutorials students said that if a post on NING clearly referred to a personal issue, they would not respond to it. This connects with Hanna and de Nooy's (2003) observation that posters in an online language-learning forum who adopted a "task-centered approach" were more successful in gaining responses than those who asked "for special student-centered experiences focussing on themselves". Hanna and de Nooy (2003) identify success with the fulfillment of the criteria for generic appropriateness. It seems that the NING posters in this project who asked for help or personal advice were failing to comply with the rhetorical rules of the blogging genre that favours other-orientation of posts.

Two factors involved here correlate with gender of poster: some research argues that in face-to-face conversation there is a tendency for males to use more directives and for females to use more modalization strategies. These gender-related preferences noted in face-to-face settings (e.g. Coates 1996, 2000; Holmes 1995; Peck 2006a) also seem to occur in online communication (Peck 2006b). The analysis of the NING site suggests that since directives gained responses and modalization did not, the rhetoric of male posts was driving high response rates. Further, since females were more likely than males to raise personal issues, this feature of their online posting also reduced responses. Orientation towards the other rather than the self appeared to be another gender-differentiated feature of online rhetoric.

The data in this project revealed that the orientation of a post towards an unspecified addressee (e.g. "Have your say") gained high response rates, while orienting a blog towards the self resulted in limited or no responses (e.g. "Advise me"; "I want to know"; "I am genuinely looking for advice on this"). A further finding was that, even when other-oriented, requests for response should be brief and unmodalized to gain responses. As discussed: "Does anyone else have any examples of lolcats, or internet memes in general, making their way into wider reference like that?" gained a response from only one member. Thus, even though it was other-oriented ("anyone else"), the request was long, complex and did not include directives. This finding is confirmed by other posts that have similar topics. The topic of short forms was framed in different ways and success rates differed: "Does anyone know whether males or females use more short forms?" received no responses, while "dU U tak lik diz? Have your say!" gained eight comments. Data from this project indicated gender-preferential linguistic tendencies and suggested alignment of success with preferred features. However, some male bloggers did not use directives, and some female bloggers did: the "internet memes" example was posted by a male, and "dU U tak IIk diz?" by a female. This suggests that the strategy, rather than gender of poster, triggered responses.

This discursive phenomenon suggested that while stalkers and lurkers read many posts, those who responded were self-interested, each wanting their own voice to be heard. The data from this project suggested that students who were skilled at initiating topics in this genre were, at some level, aware of this self-interest, and oriented their blogs towards the other: "Have your say", wrote the smart bloggers, not "Tell me". The development of 
community affinity spaces was in part driven by the skilled student bloggers' ability to engage the audience through their linguistic choices and topic selection. Blogging skill did not appear to be aligned with high academic achievement in traditional assessment tasks.

\subsubsection{Controversial Topics and "Hot" Lexical Combinations}

The most successful posts were not concerned with cyberlanguage or serious requests for advice, they were framed as contemporary and controversial topics. Some lexical items featured regularly in blogs that gained high response rates. Topics labeled "hot", or "hottest" were popular, and some interesting lexical formulations marked topics as of current interest: "Hot Topic"; "Hottest topic today"; "Newest hot topic"; "New hottest argument".

The following received the highest number of comments (25) which were posted rapidly after the post was made.

Are Men or Women better drivers? one of the hottest arguments in society.

see if we can come to a conclusion on this argument

The question in the title, the framing of the topic as "hottest argument" and the directive "see if we can come to a conclusion" were all found to be associated with successful posts. There were 15 respondents to this post (ten males and five females, aged 18-30, including local Australian and international students). This was the first overtly controversial post and it prompted students to ask whether I had "invented" the 20 year-old male student who made the original post and who was vocal in his online comebacks to other posters on the topic. This student had not spoken in class before making this post, and always sat at the back of the room. His online presence provided an effective demonstration of affinity sites' ability to engage a wide audience and facilitate diverse voices.

This post also marked a turning point in the effectiveness of the site in producing a participatory culture online, with other controversial topics with challenging invitations being posted: "What better; to be a Bitch or to be a Slut. Another social debate to name calling", posted one male, saying:

dont hold back, let loose tell us all what you really think, no matter how judgmental your opinion is.

P.S. the more ruthless the better: $\mathrm{P}$

This blog received 17 comments; "Face veil ban" received 23, and "Stalkers on Facebook", received 20. Another controversial topic: "Same sex marriage" was posted by a lesbian and received only one comment from a gay male. Other students said in tutorials that they would not post on this issue on the grounds that it was personal to the original blogger, confirming this genre's preference for other-orientation.

While the site was moderated and students were told that comments that might cause serious offence would be removed, creating a site that was representative of online social network discourse required that debate proceeded and members were largely self-monitoring. This requirement represents an ongoing challenge to instructors, and necessitates instructor evaluation of the type of presence they will adopt. Significant to this discussion was the evidence of students' self-monitoring on this site: topics that were seen as personal, (such as same-sex marriage), were avoided. Also, while students' posts involved controversy and invited "judgmental" and "ruthless" comments, the invitation was typically modified, (as with the : P emoticon in "the more ruthless the better : P"). When denigration of others was involved, posters marked themselves as belonging to the denigrated group. Thus, a poster criticizing Asian drivers identified himself as Asian, and a person commenting on the driving abilities of "rangas" identified herself as " "technically' a red-head" (ranga is an derogatory Australian colloquialism for a person with red hair). These features are probably not representative of more open social sites, and might indicate the self-monitoring of students who were aware of the diverse audience and the "ghost in the wings" (Mazzolini \& Maddison, 2003) presence of the instructor.

\subsection{Engagement in Participatory Culture: Presentations}

Online social networking succeeded in creating a culture of participation, with students from diverse backgrounds and with different abilities engaging both online and in face-to-face classes. Only two students who posted extensively online remained silent in class. The sense of community appeared to be reflected in the high confidence with which in-class presentations were delivered, and the ways in which all students collaborated to make others' presentations successful. Students posted the videos they had used in presentations to the NING site, sharing their ideas with students from the whole unit and inviting others to use their videos. Some also posted online congratulations to others: 
hey carro, really enjoyed the preso today, twas quite tasty :). well aniwho tc enjoy your week and week end and ill see you in class next week cya

Oh wow Jamie! Is that you doing a wedding? Or performing one... Umm... Or what is it called?! Ministering? Administering? Sorry $=\mathrm{o} /$ Great presentation btw.

I was impressed with your youtube selections for the presentation- I think the dog at the end is my favourite though!

I hoped for a cross over from the online network to face-to-face classes and this type of activity demonstrated the multiple layering of the process, with material from tutorial presentations being posted online, and comments on face-to-face performances being shared online with all students enrolled. The boundaries created by the structuring of face-to-face tutorial groups blurred as students "talked" online, and social literacy evolved in multi-directional ways. The social orientation of the NING site provided an interface between students' academic selves, their on-campus experiences and their off-campus lives. This type of interface was revealed in comments such as Oh wow Jamie! Is that you doing a wedding? ... Ministering? Administering? and students talked in class about Jamie's work as a minister.

\subsection{Attitudinal Shifts}

Online affinity spaces (Gee 2004) resulted in the development of "real life" affinities, with friendships on and off-campus developing, despite students' initial skepticism. Students' transition from ambivalence to acceptance of NING in this project is suggestive of the transformative possibilities of social networking for learning and teaching. Their attitudinal shift is reflected in students' online comments:

to be completely honest I was a little hesitant about ning to begin with. I thought that it was just trying to be like facebook, but then I used it and realised it was COOLER!

I think its great. it really put names to faces for me and in the end I felt more comfortable answering or contributing in class :)

I like its laid back style and that I communicate with other class members and with you jennifer and not feel like im doing the wrong thing, since its university approved :)

These comments are representative of a number of online posts, and while they do not provide objective evidence, they are supported by the results of anonymous formal unit evaluations. This paper's claim that new technologies can be used to implement fundamental change in learning and teaching is confirmed by one student's online post:

So cool that were the first bunch to use Ning ... makes me feel special, like I am part of some revolutionary movement ... [it] will open up doors to innovative learning within the university context. lol....random....

\section{Conclusion}

The project shows that new technologies can be used to implement change in learning and teaching practices. The inclusion of an online site that was designated as a social space was successful in increasing participation in face-to-face tutorials and lectures. Students' positive feedback through their blog posts and formal unit evaluations suggest that the creation of an interface between students' social and academic lives enhanced their university experience.

Blogging analysis reveals strategies that engage lurkers and stalkers, and demonstrates the salience of instructor behaviours and instructor presence to students' social engagement. The NING site is an ongoing feature of this linguistics unit, and different approaches to online teacher presence will be the subject of further research.

Males seemed to flourish in this online social environment, suggesting possibilities for the advancement of male literacy. Future research could usefully examine whether males' success in this genre involves the marginalization of female voices.

This project reveals both challenges and opportunities for education. Implementing essentially social online spaces expands teaching beyond traditional formal structures to create a participatory culture in which students share affinity spaces and teachers and learners collaborate in the education process.

\section{Acknowledgements}

My grateful thanks go to all the students in the unit at Macquarie University who contributed to the NING site. 
Many thanks also to Gabrielle Piggin for her encouragement and comments on a draft of the paper, and to Liz Shoostovian for her research assistance. I would like to thank the anonymous reviewers for their helpful feedback on an earlier version of this paper.

\section{References}

Althaus, S. L. (1997). Computer-mediated communication in the university classroom: An experiment with online discussions. Communication $\quad$ Education, 46(3), 158-174. http://dx.doi.org/10.1080/03634529709379088

Barbara, H. E., \& de Nooy, J. (2003). A funny thing happened on the way to the forum: Electronic discussion and foreign language learning. Language Learning \& Technology, 7(1), 71-85.

Chronicle. (n.d.). Retrieved May 11, http://chronicle.com/blogs/profhacker/the-creepy-treehouse-problem/23027

2011, from:

Coates, J. (1989). Gossip revisited. Language in all-female groups. In J. Coates, \& D. Cameron (Eds.), Women in Their Speech Communities (pp. 94-122). London: Longman.

Coates, J. (1996). Women Talk. Oxford: Blackwell.

Coates, J. (2000). 'So I thought bollocks to that': Men, stories and masculinities. In J. Holmes (Ed.), Gendered Speech in Social Context: Perspectives From Gown and Town (pp. 11-38). Wellington: Victoria University Press.

Davies, J., \& Graff, M. (2005). Performance in e-learning: Online participation and student grades. British Journal of Educational Technology, 36(4), 657-663. http://dx.doi.org/10.1111/j.1467-8535.2005.00542.x

$\begin{array}{llllll}\text { Flexknowledgy. } & \text { (n.d.). } & \text { Retrieved } & \text { May }\end{array}$ http://flexknowlogy.learningfield.rg/2008/04/09/defining-creepy-tree-house/

$\begin{array}{llllll}\text { Forum, } & \text { D. } & \text { (n.d.). } & \text { Retrieved } & \text { February } & 28,\end{array}$ http://www.forumdr.com/the-90-9-1-principle-applied-to-forums/764/

Garrison, D. R., Anderson, T., \& Archer, W. (1999). Critical inquiry in a text-based environment: Computer conferencing in higher education. The Internet and Higher Education, 2(2), 87-105. http://dx.doi.org/10.1016/S1096-7516(00)00016-6

Gee, J. P. (2004). Situated Language and Learning: A Critique of Traditional Schooling. New York: Routledge.

Greenhow, C., \& Robelia, B. (2009). Old communication, new literacies: Social network sites as social learning resources. Journal of Computer-Mediated Communication, 14(4), 1130-1161. http://dx.doi.org/10.1111/j.1083-6101.2009.01484.x

Herring, S., Johnson, D., \& DiBenedetto, T. (1992). Participation in electronic discourse in a "feminist" field. In K. Hall, M. Bucholtz, \& B. Moonwomon (Eds.), Locating Power 1, Proceedings of the second Berkeley women and language conference 1 and 2 (pp. 250-262). Berkeley, Cal.: Berkeley Women and Language Group.

Herring, S., Johnson, D., \& DiBenedetto, T. (1995). "This discussion is going too far!": Male resistance to female participation on the internet. In K. Hall, \& M. Bucholtz (Eds.), Gender Articulated: Language and the Socially Constructed Self (pp. 67-96). New York: Routledge.

Holmes, J. (1995). Women, Men and Politeness. London: Longman.

Jenkins, H., Clinton, K., Purushotina, R., Robinson, A. J., \& Weigel, M. (2009). Confronting the Challenges of Participatory Culture: Media Education for the $21^{\text {st }}$ Century. MacArthur.

Jones, J. B. (2010). The creepy treehouse problem. Retrieved May 11, 2011, from http://chronicle.com/blogs/profhacker/the-creepy-treehouse-problem/23027

Labov, W. (1973). Sociolinguistic Patterns. Philadelphia: University of Pennsylvania Press.

Mazzolini, M., \& Maddison, S. (2003). Sage, guide or ghost? The effect of instructor intervention on student participation in online discussion forums. Computers \& Education, 40(3), 237-253. http://dx.doi.org/10.1016/S0360-1315(02)00129-X

Merchant, G. (2007). Mind the gap(s): Discourses and discontinuity in digital literacies. E-Learning, 4(3), 241-255. http://dx.doi.org/10.2304/elea.2007.4.3.241

Nielsen, J. (2006). Participation inequality: Encouraging more users to contribute. Retrieved February 8, 2011, 
from htttp://www.useit.cpm/alertbox/participation_inequality.html.

Parsell, M., \& Duke-Yonge, J. (2007). Virtual communities of enquiry: An argument for their necessity and advice for their creation. E-Learning, 4(2), 181-193. http://dx.doi.org/10.2304/elea.2007.4.2.181

Peck, J. J. (2006a). Women and promotion: The influence of communication style. In M. Barrett, \& M. J. Davidson (Eds.), Gender and Communication at Work (pp. 50-66). Aldershot: Ashgate.

Peck, J. J. (2006b). CMC: In search of cyberidentities. Paper presented at The 2006 ALS Conference, 7-9 July. The University of Queensland, St Lucia, Brisbane, Australia.

Plester, B., \& Wood, C. (2009). Exploring relationships between traditional and new media literacies: British preteen texters at school. Journal of Computer-Mediated Communication, 14(4), 1108-1129. http://dx.doi.org/10.1111/j.1083-6101.2009.01483.x

Reber, T. C. (1996). Giving voice to the silent ones: electronic discussion in a college literature course. Journal of Staff, Program, and Organizational Development, 13, 147-153.

Swan, K., \& Shea, P. (2005). The development of virtual learning communities. In S. R. Hiltz, \& R. Goldman, (Eds.), Learning Together Online: Research on Asynchronous Learning Networks (pp. 239-297). Mahwah, N. J.: Lawrence Erlbaum.

Tannen, D., \& Saville-Troike, M. (Eds.). (1985). Perspectives on Silence. Norwood, N.J.: Ablex.

Thompson, T. L., \& Mac Donald, C. J. (2005). Community building, emergent design and expecting the unexpected: Creating a quality eLearning experience. The Internet and Higher Education, 8(3), 233-249. http://dx.doi.org/10.1016/j.iheduc.2005.06.004

Wallace, P., \& Howard, B. (2010). Social networking tools to facilitate cross-program collaboration. Educause Quarterly, 33(4).

Webb, E. (2009). Engaging students with engaging tools. Educause Quarterly, 32(4). 